\title{
Design Methodology for Supply Water Distribution Network; Case Study: Al-Hadeka District, Garaboulli- Libya
}

\author{
Khairi Algrad, Abdulghani Ramadan* \\ Department of Mechanical Engineering, Faculty of Engineering, Elmergib University, Libya \\ DOI: https://doi.org/10.21467/proceedings.4.34 \\ * Corresponding author email: amramadan@elmergib.edu.ly
}

\begin{abstract}
Pipe network is a hydraulic network containing several or many inter-connected branches where fluid (water) flows through it. This paper presents a design methodology for a supply water pipe network for Al-Hadeka district at Garaboulli-Libya. The proposed network provides water to 150 residential units with an average occupation density of 7 persons per unit. The main objective is to determine the flow rate and pressure head at each individual section of the network in addition to water demand of the region. The governing differential equations were formulated based on the continuity and the energy equations. Hardy Cross Method and EPANET Software were implemented to perform the calculations. Two cases were analyzed and investigated, namely, gravity flow and forced flow. Results of both cases were interpreted and compared. There is a good agreement between the results of both methods, in terms of flow velocities in pipes and pressure heads. These values lie in the allowable range in accordance with the known standards and specifications for water distribution networks. The use of the available software, EPANET, for analysis saves time and effort and gives acceptable results of appropriate precision.
\end{abstract}

Keywords: Pipe network, Hardy Cross, EPANET, Gravity flow, Forced flow.

\section{Introduction}

Water distribution networks serve many purposes in addition to the provision of water for human consumption. Piped water is used for washing, sanitation, irrigation and fire fighting. Networks are designed to meet peak demands; in parts of the network this creates low-flow conditions that can contribute to the deterioration of microbial and chemical water quality. The purpose of a system of pipes is to supply water at adequate pressure and flow. However, pressure is lost by the action of friction at the pipe wall and pipe accessories and fittings such as valves, elbows...etc. The pressure loss is also dependent on the water demand, pipe length, gradient and diameter. Several established empirical equations describe the pressure-flow relationship and these have been incorporated into network modelling software packages to facilitate their solution and use. Traditionally, a water distribution network design is based on the proposed street plan and the topography. Various equations have been used in this study (C) 2018 Copyright held by the author(s). Published by AIJR Publisher in Proceedings of First Conference for Engineering

Sciences and Technology (CEST-2018), September 25-27, 2018, vol. 2 .
This is an open access article under Creative Commons Attribution-NonCommercial 4.0 International (CC BY-NC 4.0) license, which permits any non-commercial use, distribution, adaptation, and reproduction in any medium, as long as the original work is properly cited. ISBN: 978-81-936820-6-7 
as the continuity equation and the energy equation. Hardy Cross Method and EPANET Software was used to perform the calculations required. The hydraulic analysis for the network is applied to two cases, gravity flow and forced flow. Extensive research work on supply water networks has been carried out in literature. For example, studies as shown in references [1], [2], [3], [4] \& [5]. Generally, they focused on designing and analyzing supply water pipe networks by Hardy Cross method and EPANET software. Flow rates and pressure heads at each node and junction in the network are calculated and determined. Comparison of results were also interpreted and discussed.

\section{Site Overview}

The site is located in Al-Hadeka district at Al-Garaboulli city, with an area of $31125 \mathrm{~m}^{2}$ and 150 housing utilities as shown in Figure 1.

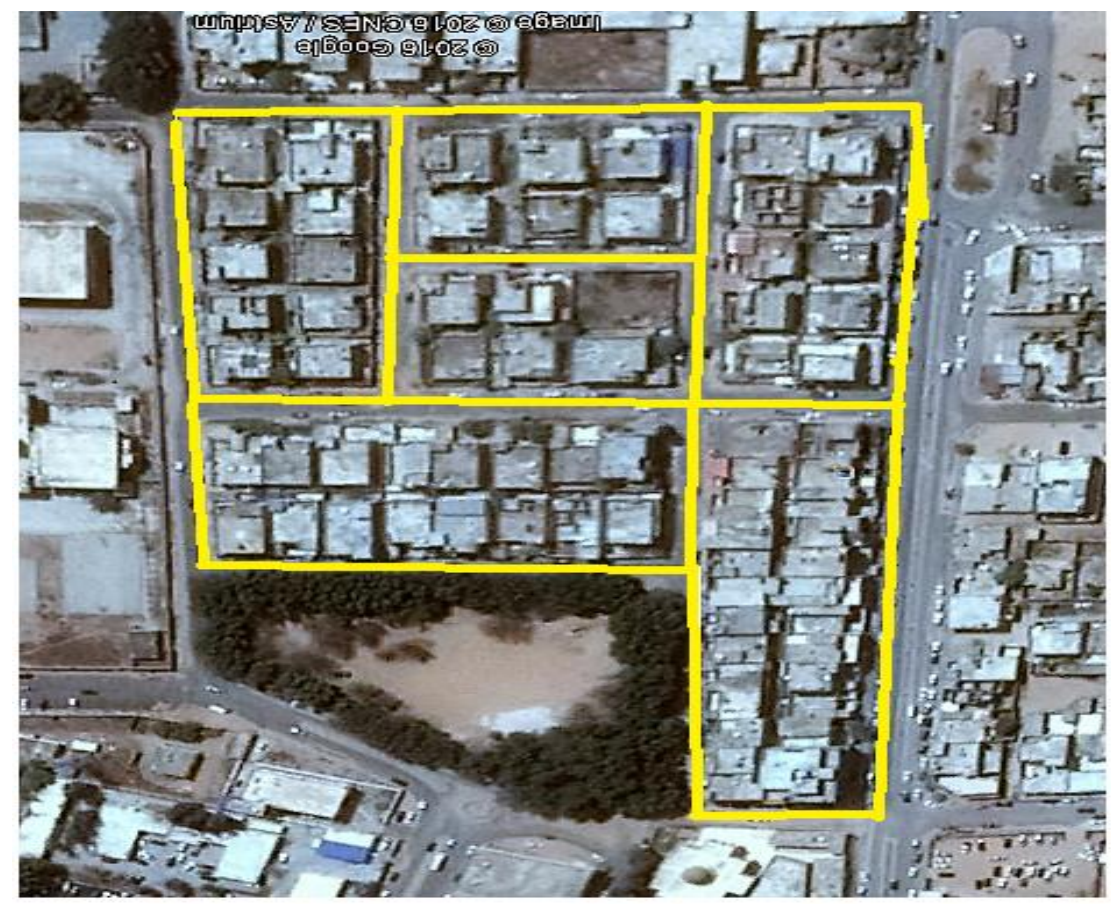

Figure 1: Site Overview for Al-Hadeka district at Al-Garaboulli city.

According to population surveys in Libya, in the year 2014, it was found that the family member average is 7 persons, this was done with the help of population private data of the previous years, this comprehensive population scanning is done regularly every 10 years, amongst the methods used for future population scanning is the Geometric Method. Accordingly, population of this area is approximated to be 1050 persons and Water consumption rate is $270 \mathrm{Litre} /$ day/person, so that the total water demand is about 284 $m^{3} /$ day [6]. 
Design Methodology for Supply Water Distribution Network; Case Study: Al-Hadeka District, Garaboulli-Libya

\section{Design Methodology}

\subsection{Hardy Cross Method}

Hardy Cross method is an effective method in pipe networks analysis. The Hardy Cross method of analysis is a simplified version of the iteration linear analysis. This method is mainly based on assuming reasonable starting values for water flow rates inside network pipes and their directions according to the proposed loops. Then, the values of flow rates should be adjusted iteratively in order to reach to an optimum and precise approximation. Moreover, the head loss in pipes is evaluated simultaneously. In order to apply this method, the site is divided into many subdivisions and loops as shown in Figure 2.

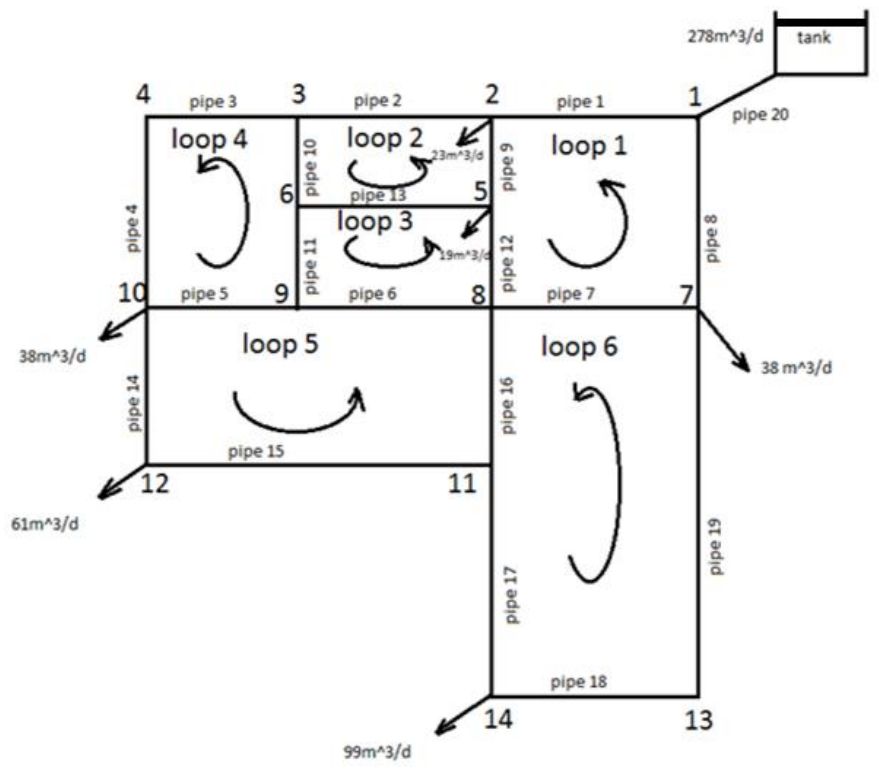

Figure 2: Schematic drawing for pipe network nodes, junctions and loops.

\subsection{EPANET Software}

EPANET Software, as shown in Figure 3, performs extended period simulation of hydraulics and pipe network analysis. Moreover, it is designed to be applicable also to pressurized pipe networkers. A pipe network consists of pipe, nodes (pipe junctions), pumps, valves and storage tanks or reservoirs. EPANET evaluates the flow rates of the water in each pipe, the pressure at each node. EPANET provides an integration environment for editing network input data, performing hydraulic analysis, and viewing the result in a variety of formats, these include colour- coded network maps, data tables, time series graphs, and contour plots. EPANET was developed by the Water Supply and Water Resources Division of the U.S. Environmental Protection Agency. 
Algrad et al., CEST-2018, AIJR Proceedings 4, pp.665-674, 2018

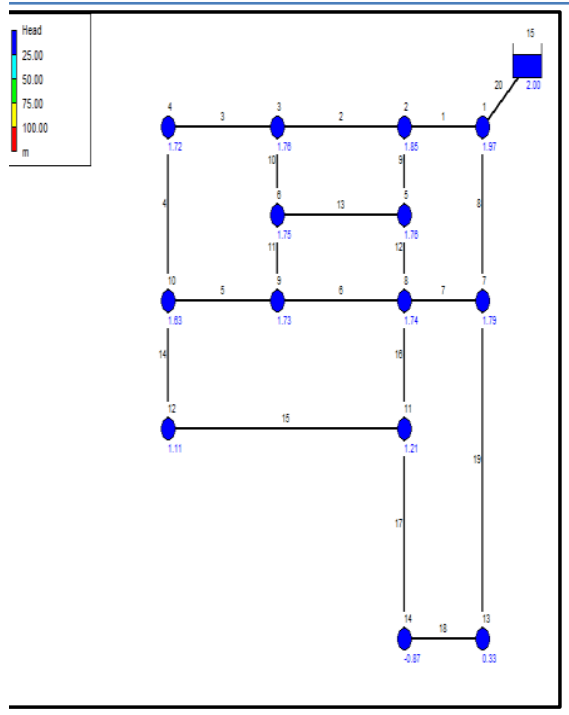

(a)

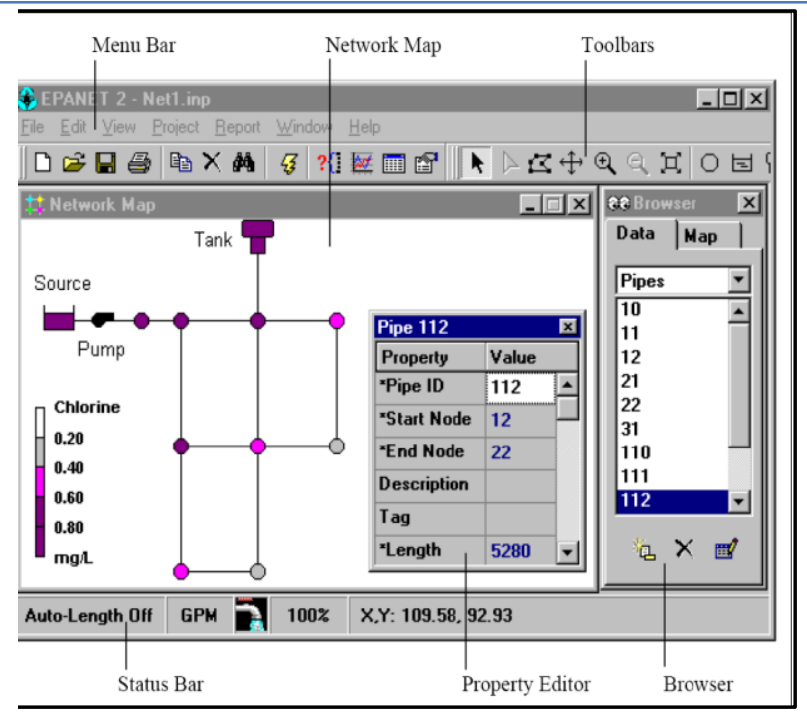

(b)

Figure 3: Pipe network analysis by EPANET
(a) Present study pipe network.
(b) EPANET software interface.

\subsection{Solution Procedure}

Following are the steps carried out to model water distribution network using Hardy Cross method and EPANET;

Step 1: Draw a network representation of distribution system.

Step 2: Edit the properties of the objects that make up the system. It includes editing the properties and entering required data in various objects like reservoir, pipes, nodes and junctions.

Step 3: Describe how the system is operated.

Step 4: Select a set of analysis option.

Step 5: Run a hydraulic analysis program/software.

Step 6: View the results of the analysis which can be viewed in various forms i.e. in the form of tables or graphs.

In addition, the pipe network design and operating conditions for this study according to known standards and specifications, [6] are as follows;

- Flow velocity inside pipes ranges from (0.1 to 1.5$) \mathrm{m} / \mathrm{s}$.

- The allowable pressure at nodes ranges from (1.5 to 3$)$ bar.

- Pipe diameters range from (32 to 110) $\mathrm{mm}$.

- Pipe material is HDPE can withstand pressure up to 6 bar.

In order to simplify the analysis, some assumptions are also considered as follows;

- Secondary losses inside pipe network fittings and other accessories are assumed to be negligible. 
Design Methodology for Supply Water Distribution Network; Case Study: Al-Hadeka District, Garaboulli-Libya

- Pipes are located at the same level inside the study area.

Storage tank capacity of $900 \mathrm{~m}^{3}$ provides water to site at least for 3 days in case of emergency.

\section{$4 \quad$ Results and Discussion}

The hydraulic analysis for the pipe distribution network is applied to two design scenarios, namely, gravity flow case and forced flow case (using a pump).

\subsection{Case I: (Gravity Flow)}

In the first case the water level on the reservoir is located just 2 meters above ground surface. Results of Hardy Cross method are shown in Table 1 and Table 2.

Table 1: Output results of water flow rates in pipes.

\begin{tabular}{|c|c|c|c|}
\hline Link ID & $\begin{array}{c}\mathrm{Q} \\
\left(\mathrm{m}^{3} / \mathrm{s}\right)\end{array}$ & $\begin{array}{c}\mathrm{Q} \\
(\mathrm{L} / \mathrm{s})\end{array}$ & $\begin{array}{c}\mathrm{Q} \\
\left(\mathrm{m}^{3} / \mathrm{day}\right)\end{array}$ \\
\hline Pipe 1 & 0.001808 & 1.808 & 156.2112 \\
\hline Pipe 2 & 0.000726 & 0.726 & 62.7264 \\
\hline Pipe 3 & 0.000572 & 0.572 & 49.4208 \\
\hline Pipe 4 & 0.000572 & 0.572 & 49.4208 \\
\hline Pipe 5 & 0.000483 & 0.483 & 41.7312 \\
\hline Pipe 6 & 0.00011 & 0.11 & 9.504 \\
\hline Pipe 7 & 0.000351 & 0.351 & 30.3264 \\
\hline Pipe 8 & 0.00141 & 1.41 & 121.824 \\
\hline Pipe 9 & 0.000816 & 0.816 & 70.5024 \\
\hline Pipe 10 & 0.000154 & 0.154 & 13.3056 \\
\hline Pipe 11 & 0.000377 & 0.377 & 32.5728 \\
\hline Pipe 12 & 0.000373 & 0.373 & 32.2272 \\
\hline Pipe 13 & 0.000223 & 0.223 & 19.2672 \\
\hline Pipe 14 & 0.000615 & 0.615 & 53.136 \\
\hline Pipe 15 & $9.1 \mathrm{E}-05$ & 0.091 & 7.8624 \\
\hline Pipe 16 & 0.000619 & 0.619 & 53.4816 \\
\hline Pipe 17 & 0.000528 & 0.528 & 45.6192 \\
\hline Pipe 18 & 0.00062 & 0.62 & 53.568 \\
\hline Pipe 19 & 0.00062 & 0.62 & 53.568 \\
\hline Pipe 20 & 0.00322 & 3.22 & 278.208 \\
\hline
\end{tabular}

Table 2: Head values at each node.

\begin{tabular}{|c|c|}
\hline Node ID. & Head (m) \\
\hline 1 & 1.97 \\
\hline 2 & 1.85 \\
\hline 3 & 1.76 \\
\hline 4 & 1.72 \\
\hline 5 & 1.76 \\
\hline 6 & 1.75 \\
\hline 7 & 1.79 \\
\hline 8 & 1.74 \\
\hline 9 & 1.73 \\
\hline 10 & 1.63 \\
\hline 11 & 1.21 \\
\hline 12 & 1.11 \\
\hline 13 & 0.33 \\
\hline 14 & -0.87 \\
\hline & \\
\hline
\end{tabular}

Results from EPANET software are shown in Table 3. Flow rates at each pipe, flow velocity, unit head loss and friction factor are determined. 
Algrad et al., CEST-2018, AIJR Proceedings 4, pp.665-674, 2018

Table 3: EPANET output results for case I.

\begin{tabular}{|c|c|c|c|c|}
\hline Link ID & $\begin{array}{l}\text { Flow rate } \\
\left(\mathrm{m}^{3} / \text { day }\right)\end{array}$ & Velocity $(\mathrm{m} / \mathrm{s})$ & $\begin{array}{l}\text { Unit Head loss } \\
\qquad(\mathrm{m} / \mathrm{km})\end{array}$ & Friction factor \\
\hline Pipe 1 & 1.2615 & 0.40 & 72.8 & 0.025 \\
\hline Pipe 2 & 95.16 & 0.22 & 71.2 & 0.030 \\
\hline Pipe 3 & 44.48 & 0.27 & 820. & 0.031 \\
\hline Pipe 4 & 44.48 & 0.17 & 820. & 0.031 \\
\hline Pipe 5 & 61.42 & 0.27 & 2 & 10.03 \\
\hline Pipe 6 & 9.401 & 20.1 & 130. & 40.03 \\
\hline Pipe 7 & 23.03 & 0.19 & 01.1 & 0.034 \\
\hline Pipe 8 & 9.7112 & 0.32 & 31.8 & 0.026 \\
\hline Pipe 9 & 26.17 & 0.27 & 631. & 0.029 \\
\hline Pipe 10 & 51.31 & 20.1 & 070. & 340.0 \\
\hline Pipe 11 & 13.32 & 0.14 & 400. & 50.03 \\
\hline Pipe 12 & 64.33 & 0.16 & 430. & 40.03 \\
\hline Pipe13 & 26.81 & 0.10 & 160. & 10.04 \\
\hline Pipe 14 & 05.35 & 0.48 & 58.7 & 0.029 \\
\hline Pipe 15 & 95.7 & 0.12 & 50.8 & 0.041 \\
\hline Pipe 16 & 7453. & 0.50 & 888. & 0.029 \\
\hline Pipe 17 & 5245. & 0.65 & 219.8 & 0.029 \\
\hline Pipe 18 & 4853. & 0.77 & 6326. & 0.028 \\
\hline Pipe 19 & 4853. & 0.49 & 888. & 0.029 \\
\hline Pipe 20 & 278.00 & 0.34 & 1.26 & 0.024 \\
\hline
\end{tabular}

From above results, Table 2 clearly shows that at node no. 14, the value of pressure head is negative. This means that the pressure at this node is less than atmospheric pressure which in turn implies that water will not reach the node and hence it is clear that the height of the elevated reservoir in case I, is undersized. Therefore, the water reservoir should be located at higher elevation. For this purpose, the tank is elevated at $20 \mathrm{~m}$ above ground surface level, this is considered as case II.

\subsection{Case II: Gravity Flow using Elevated Tank}

Because of the negative pressure in the case I, the tank height will be change to $20 \mathrm{~m}$ above ground. The obtained results of both Hardy Cross and EPANET are shown and compared in Table 4 and Table 5.

Proceedings of First Conference for Engineering Sciences and Technology (CEST-2018), vol. 2 670 
Design Methodology for Supply Water Distribution Network; Case Study: Al-Hadeka District, Garaboulli-Libya

Table 4: Comparison of results for pressure head in case II.

\begin{tabular}{|c|c|c|c|}
\hline \multirow{2}{*}{ Node ID } & $\begin{array}{c}\text { Head, H-C } \\
(\mathrm{m})\end{array}$ & $\begin{array}{c}\text { Head, Epanet } \\
(\mathrm{m})\end{array}$ & Error, \% \\
\hline 1 & 19.98278 & 19.97 & 0.06397 \\
\hline 2 & 19.89224 & 19.85 & 0.212357 \\
\hline 3 & 19.83574 & 19.76 & 0.381859 \\
\hline 4 & 19.81069 & 219.7 & 0.457766 \\
\hline 5 & 19.84119 & 619.7 & 0.409176 \\
\hline 6 & 19.8304 & 519.7 & 0.405418 \\
\hline 7 & 19.86057 & 19.79 & 0.355338 \\
\hline 8 & 19.83201 & 19.74 & 0.463942 \\
\hline 9 & 19.82799 & 319.7 & 0.494182 \\
\hline 10 & 19.76803 & 319.6 & 0.698249 \\
\hline 11 & 19.45122 & 119.2 & 1.240142 \\
\hline 12 & 19.50449 & 1119. & 2.022568 \\
\hline 13 & 18.81528 & 318.3 & 2.579171 \\
\hline 14 & 17.88649 & 317.1 & 4.22941 \\
\hline
\end{tabular}

Table 5: Comparison of results for flow rates in case II.

\begin{tabular}{|c|c|c|c|}
\hline Link ID & $\mathrm{Q}\left(\mathrm{m}^{3} /\right.$ day $) \mathrm{H}-\mathrm{C}$ & $\mathrm{Q}\left(\mathrm{m}^{3} /\right.$ day $)$ Epanet & Error, $\%$ \\
\hline Pipe 1 & 156.2112 & 1.2615 & 0.000768 \\
\hline Pipe 2 & 62.7264 & 95.16 & 1.237756 \\
\hline Pipe 3 & 49.4208 & 44.48 & 1.984589 \\
\hline Pipe 4 & 49.4208 & 44.48 & 1.984589 \\
\hline Pipe 5 & 41.7312 & 61.42 & 2.10586 \\
\hline Pipe 6 & 9.504 & 9.410 & 10.5397 \\
\hline Pipe 7 & 30.3264 & 23.30 & 0.021104 \\
\hline Pipe 8 & 121.824 & 9.7112 & 0.027909 \\
\hline Pipe 9 & 70.5024 & 26.17 & 1.07457 \\
\hline Pipe 10 & 13.3056 & 51.31 & 1.5362 \\
\hline Pipe 11 & 32.5728 & 13.32 & 4.38387 \\
\hline Pipe 12 & 32.2272 & 64.33 & 3.359077 \\
\hline Pipe13 & 19.2672 & 26.81 & 0.161849 \\
\hline Pipe 14 & 53.136 & 05.35 & 1.11416 \\
\hline Pipe 15 & 7.8624 & 95.7 & 0.02169 \\
\hline Pipe 16 & 53.4816 & 7453. & 0.217452 \\
\hline Pipe 17 & 45.6192 & 5245. & 0.164277 \\
\hline Pipe 18 & 53.568 & 4853. & 0.164277 \\
\hline Pipe 19 & 53.568 & 4853. & \\
\hline
\end{tabular}


It should be noted that no negative pressure head values are noticed. The assumption of elevating the water tank to a height of $20 \mathrm{~m}$ is reasonable and logic. Moreover, the comparison between the results from Hardy Cross method and EPANET shows a good agreement between results of both methods.

\subsection{Case III: Forced flow Using Pump}

Another alternative for solving the problem of negative pressure in case I, is based on using a ground water tank equipped with a pump station. In this case, water is forced to flow into the pipe distribution network ensuring suitable water demands and pressure heads values at pipes' nodes. Figure 4 shows the characteristics curve for the chosen pump to be used in the system and analyzed by EPANET Software simulation.

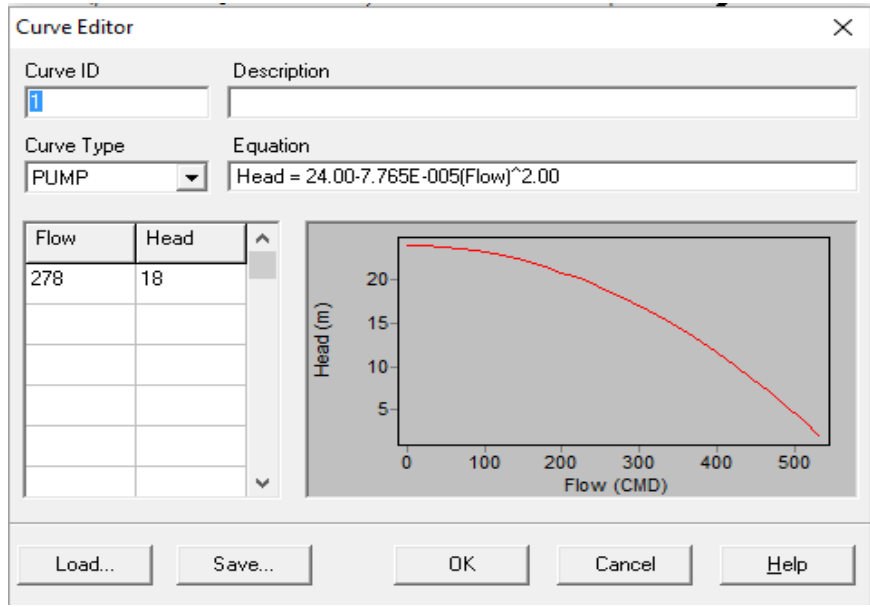

Figure 4: Characteristic curve of the chosen pump.

Table 6 and Table 7 show the results for case III when a pump is considered in the pipeline.

Table 6: Results for demand and pressure head at each node for case III.

\begin{tabular}{|c|c|c|}
\hline Node ID & Demand $\left(\mathrm{m}^{3} /\right.$ day $)$ & Head $(\mathrm{m})$ \\
\hline 1 & 0 & 20 \\
\hline 2 & 23 & 19.87 \\
\hline 3 & 0 & 19.78 \\
\hline 4 & 0 & 19.74 \\
\hline 5 & 19 & 19.79 \\
\hline 6 & 0 & 19.78 \\
\hline 7 & 38 & 19.82 \\
\hline 8 & 0 & 19.77 \\
\hline 9 & 0 & 19.76 \\
\hline 10 & 38 & 19.66 \\
\hline 11 & 0 & 19.24 \\
\hline 12 & 61 & 19.13 \\
\hline 13 & 0 & 18.35 \\
\hline 14 & 99 & 17.15 \\
\hline
\end{tabular}

Proceedings of First Conference for Engineering Sciences and Technology (CEST-2018), vol. 2 672 
Design Methodology for Supply Water Distribution Network; Case Study: Al-Hadeka District, Garaboulli-Libya

Table 7: Results for flow rate, velocity, unit head loss and friction factor for case III.

\begin{tabular}{|c|c|c|c|c|}
\hline Link ID & $\begin{array}{c}\text { Flow rate } \\
\left(\mathrm{m}^{3} / \mathrm{day}\right)\end{array}$ & Velocity $\mathrm{m} / \mathrm{s}$ & $\begin{array}{c}\text { Unit Head loss } \\
\mathrm{m} / \mathrm{km}\end{array}$ & Friction factor \\
\hline Pipe 1 & 156.21 & 0.40 & 2.84 & 0.025 \\
\hline Pipe 2 & 61.95 & 0.22 & 0.93 & 0.030 \\
\hline Pipe 3 & 48.44 & 0.27 & 0.93 & 0.031 \\
\hline Pipe 4 & 48.44 & 0.17 & 1.73 & 0.031 \\
\hline Pipe 5 & 42.61 & 0.27 & 0.46 & 0.032 \\
\hline Pipe 6 & 10.49 & 0.12 & 1.16 & 0.034 \\
\hline Pipe 7 & 30.32 & 0.19 & 1.86 & 0.026 \\
\hline Pipe 8 & 121.79 & 0.32 & 0.48 & 0.029 \\
\hline Pipe 9 & 71.26 & 0.27 & 0.57 & 0.042 \\
\hline Pipe 10 & 13.51 & 0.12 & 0.61 & 0.037 \\
\hline Pipe 11 & 32.13 & 0.14 & 0.49 & 0.033 \\
\hline Pipe 12 & 33.64 & 0.16 & 8.74 & 0.042 \\
\hline Pipe13 & 18.62 & 0.10 & 0.89 & 0.029 \\
\hline Pipe 14 & 53.05 & 0.48 & 8.94 & 0.041 \\
\hline Pipe 15 & 7.95 & 0.12 & 19.89 & 0.029 \\
\hline Pipe 16 & 53.47 & 0.50 & 0.032 & 0.028 \\
\hline Pipe 17 & 45.52 & 0.65 & 0.77 & 0.029 \\
\hline Pipe 18 & 53.48 & 0.49 & & \\
\hline Pipe 19 & 53.48 & & & 0.929 \\
\hline
\end{tabular}

In the case of water supply from ground tank using a pump, case III, it is found that the pressure head at the end of each junction (node) and corresponding value of flow rate are acceptable and ensure providing water to consumers. Furthermore, it can be noticed that the velocities at each pipe in Table 7 are within the recommended range stated in the relevant standards.

\section{Conclusions}

In this paper, Hardy Cross Method and EPANET software were used to perform the required calculations and the hydraulic analysis for the network under study, Al-Hadeka district at Garaboulli city -Libya. Two Scenarios were proposed, gravity flow and forced flow. For gravity flow, Case I, water level in the storage tank is assumed to be 2 meters above the ground. Results show that there is a deficiency in providing the required water quantities at some nodes in the network. In order to correct the situation, storage tank elevation is adjusted to 20 meters above ground, case II. Results indicate that the flow rates and pressure heads among the junctions of the pipe networks are acceptable and lie in the allowable values.

Another alternative is to apply a pump in the network, case III, forced flow. As expected, there is a better output results in terms of flow rates, velocities in pipes and pressure heads at the required points of demand. The obtained values were found to be within the allowed ranges 
Algrad et al., CEST-2018, AIJR Proceedings 4, pp.665-674, 2018

in accordance with the specifications and standards for water distribution networks. Finally, the use of available software for analysis saves time and effort and gives results of appropriate precision.

\section{References}

[1] I.I. Nwajuaku, Y.M. Wakawa, O.J. Adibeli, "Analysis of Head-loss Equations under EPANET and Hardy Cross Method," Saudi Journal of Engineering and Technology, vol.2, issue 3, pp. 125-134, Mar, 2017.doi: 10.21276/sjeat.2017.2.3.1.

[2] A. E. Adeniran and M. A. Oyelowo, "An EPANET Analysis of Water Distribution Network of the University of Lagos, Nigeria," Journal of Engineering Research, Volume 18, No. 2, June 2013.

[3] N. Moosavian, M. R. Jaefarzadeh, "Hydraulic Analysis of Water Supply Networks Using a Modified Hardy Cross Method," International Journal of Engineering Transactions, Vol. 27, No. 9, pp 1331-1338, Sep. 2014.

[4] G. Venkata Ramanaa , V. S. S. Sudheer , B.Rajasekhar, "Network analysis of water distribution system in rural areas using EPANET,” Procedia Engineering, vol. 119, pp 496-505, 2015.

[5] R.K.Rai, N.G. Sanap, "Analysis of Hydraulic Network using Hardy Cross Method and EPANET," International Journal of Innovative Research in Science and Engineering, vol3, issue 3, pp 516-522, Mar. 2017.

[6] "Design Standard", Housing and Infrastructure Board, HIB, Tajoura, Libya, Aug. 2008. 